UDC 621.039

\title{
ANALYSIS OF THE SETUP AND PARAMETERS OF THE FNS-ST TOKAMAK FAST ATOM INJECTOR
}

\author{
A.A. Panasenkov, S.S. Ananyev, E.D. Dlougach, B.V. Kuteev
}

NRC «Kurchatov Institute», Moscow, Russia

A Fusion Neutron Source (FNS) based on Spherical Tokamak (ST), now being developed, is expected to produce a high-yield (up to $10^{18} \mathrm{~s}^{-1}$ ) neutron flux via in-plasma stationary current generation with a beam of fast atoms [1-3]. This study is concerned with the selection of the setup and parameters of a fast deuterium atom injector for the FNS-ST neutral injection system. Fast atom energy is important for determining the efficiency of current generation in tokamak plasma and estimating the neutron yield. Different injector setup versions based on positive- and negative-ion sources were tested, and the one selected based on sources of positive deuterium ions with energies $\leq 140 \mathrm{keV}$. An injection module allowing the delivery of 3.5 MW deuterium neutral beam power to plasma is considered.

Key words: fusion neutron source, tokamak, injector, ion source, neutral beam.

DOI: 10.21517/0202-3822-2021-44-2-86-99

\section{АНАЛИЗ СХЕМЫ И ПАРАМЕТРЫ ИНЖЕКТОРА БЫСТРЫХ АТОМОВ ДЛЯ ТОКАМАКА ТИН-СТ \\ А.А. Панасенков, С.С. Ананьев, Е.Д. Длугач, Б.В. Кутеев}

НИЦ «Курчатовский институт», Москва, Россия

В разрабатываемом проекте термоядерного источника нейтронов на основе сферического токамака ТИН-СТ предполагается возможность стационарной генерации тока в плазме с помощью пучка быстрых атомов, что обеспечивает высокий уровень (до $10^{18} \mathrm{c}^{-1}$ ) потока нейтронов [1-3]. Данная работа посвящена выбору схемы и параметрам инжектора быстрых атомов дейтерия для системы нейтральной инжекции токамака ТИН-СТ. Энергия быстрых атомов является важным параметром, определяющим эффективность генерации тока в плазме токамака и нейтронный выход. Рассмотрены схемы инжекторов на основе источников пучков положительных и отрицательных ионов и выбран вариант с использованием источников положительных ионов дейтерия с энергиями до $\leq 140$ кэВ. Рассмотрен вариант инжекторного модуля с мощностью вводимого в плазму пучка атомов дейтерия на уровне 3.5 МВт.

Ключевые слова: термоядерный источник нейтронов, токамак, инжектор, источник ионов, пучок быстрых атомов.

\section{INTRODUCTION}

Fusion neutron sources (FNS) are considered promising for applications, such as testing of struc-tural materials for future nuclear and thermonuclear reactors, nuclear waste disposal research, fuel production and testing of hybrid reactor technologies. Spherical tokamaks have better plasma stability and confinement characteristics than their classical counterparts. They can be used as a template for smaller neutron sources capable of providing a high stationary neutron flux at a lower cost [1-3].

A FNS-ST (Spherical Tokamak)-based thermonuclear neutron source project, now being designed, is anticipated to produce a high-yield (up to $10^{18} \mathrm{~s}^{-1}$ ) neutron flux via in-plasma stationary current generation with a beam of fast atoms [1-3]. This study is concerned with the selection of the setup and parameters of a fast deuterium atom injector for the FNS-ST neutral injection system. Fast atom energy is important for determining the efficiency of current generation in tokamak plasma and estimating the neutron yield. It has been shown in [2] that in the $100-200 \mathrm{keV}$ range, the fraction of neutrons generated via $\mathrm{D}-\mathrm{T}$ reactions in the thermal component of the plasma decreases with increasing beam energy, while the total neutron yield grows due to rising intensity of $\mathrm{D}-\mathrm{T}$ reactions associated with the beam-plasma interaction. Another effect of beam energy increase is a noticeable enhancement of plasma current generation efficiency. How-ever, beam energy increase is capped by the relatively small plasma size. In fact, a neutral beam (NB) fraction passing through the plasma without being captured also grows with increasing energy, im-parting a significant power load onto the tokamak first wall.

FNS-ST's key characteristics are as follows:

Large radius $R, \mathrm{~m} \ldots$

0.5

Small radius $a, \mathrm{~m} .$.

0.3

Elongation $k \ldots$

Toroidal magnetic field $B_{\mathrm{T}}, \mathrm{T} \ldots$

1.5 
Plasma current $I_{\mathrm{P}}, \mathrm{MA} \ldots$

Average plasma density, $\mathrm{m}^{-3} \ldots$
$1.5 \mathrm{MA}$

$(0.5-1) 10^{20}$

The NB power, $P_{\text {inj }}=6-10 \mathrm{MW}$, is delivered to the plasma by three operating injectors. The NB enters the tokamak chamber through a $0.3 \times 0.6 \mathrm{~m}$ entrance window.

Selection of the ion types and energy. From the viewpoint of the NB injection efficiency, the 100$200 \mathrm{keV}$ beam energy range, proposed for FNS-ST, is an intermediate case, where both positive and negative ion technology (PI and NI, respectively) may be used. This is due to the neutralization efficiency of deuterium ions in the gas target with energy increasing, which remains at a level of about $60 \%$ for NI and rapidly decreases for PI. Fig. 1 demonstrates the equilibrium yield $\left(\Phi_{0}\right)$ of $\mathrm{D}^{0}$ atoms as a function of energy released in the $\mathrm{D}^{+}$neutralization of in a «thick» deuterium target [4] (target thickness: $\left.\tau=\int n_{\mathrm{o}}(x) d x\right)$. In fact, this dependence reflects the efficiency of PI neutralization in the beam current $\left(\Phi_{\mathrm{I}}=\Phi_{0}\right)$. By multiplying $\Phi_{0}$ by corresponding ion energy value we obtain a curve representing neutralization efficiency in terms of power $\left(\Phi_{\mathrm{P}}\right)$, where power is expressed in terms of atoms obtained per ampere of source ion current at different energies. For deuterium PI case, this dependence has a maximum of about $52 \mathrm{~kW} / \mathrm{A}$ at an energy of around $100 \mathrm{keV}$ (Fig. 2). In the NI case, the $\Phi_{\mathrm{P}}$ value grows almost linearly by a factor of around 0.6 with increasing ion energy. Consequently, with the rise of the ion energy, to obtain a neutral beam of a given power with the PI technology a significant increase in the current and power of the beam from the source is required, while in the NI case the required ion current decreases noticeably at an almost constant beam power (Fig. 3).

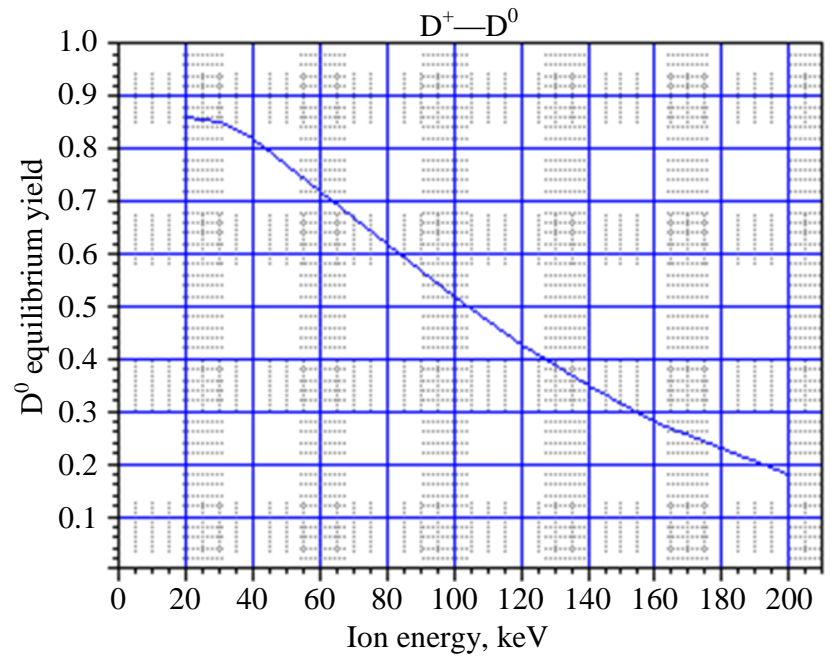

Fig. 1. Equilibrium yield of $\mathrm{D}^{0}$ atoms upon neutralization of $\mathrm{D}^{+}$ ions in a «thick» gas target

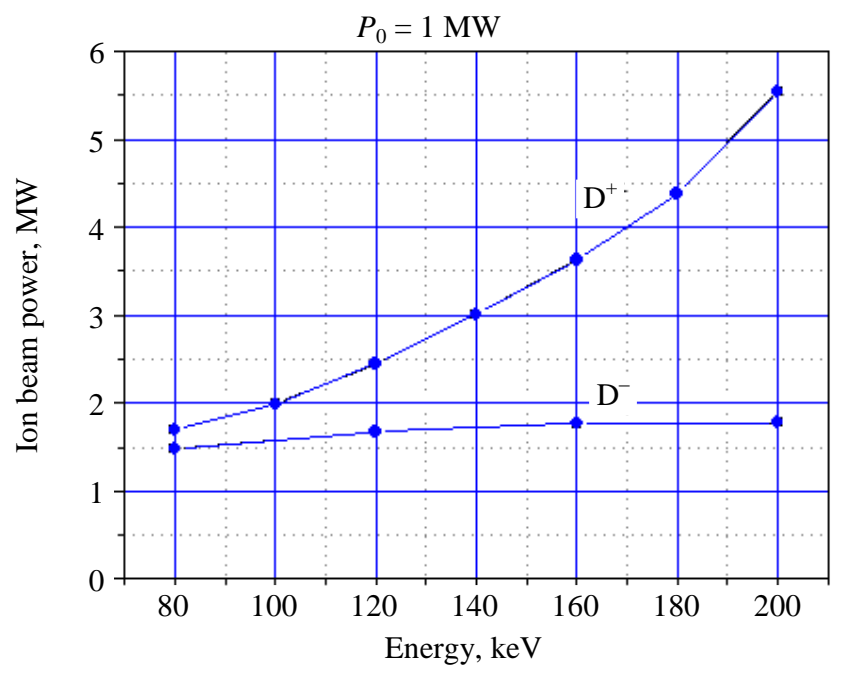

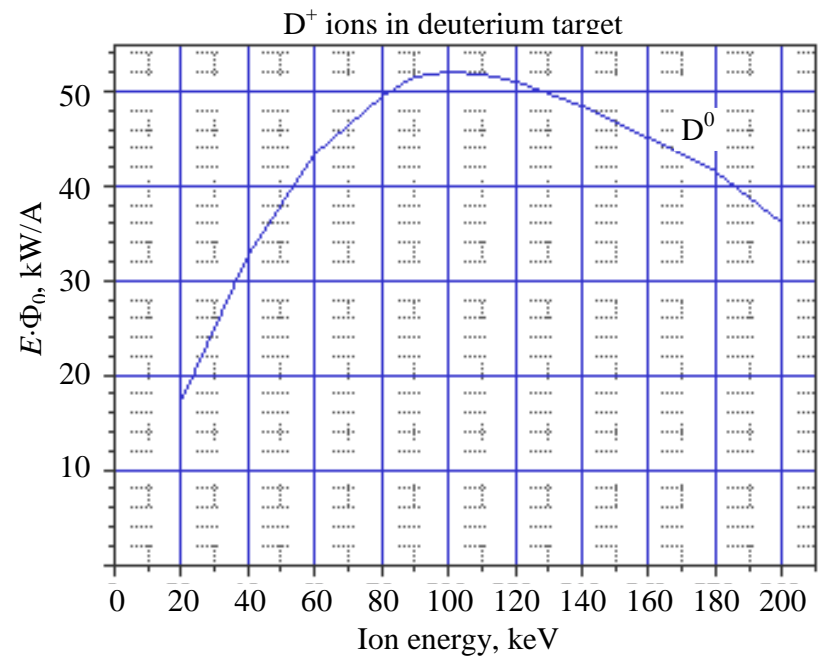

Fig. 2. Efficiency of neutralization by power $\left(\Phi_{\mathrm{P}}\right)$ of $\mathrm{D}^{+}$ions in a «thick» gas target

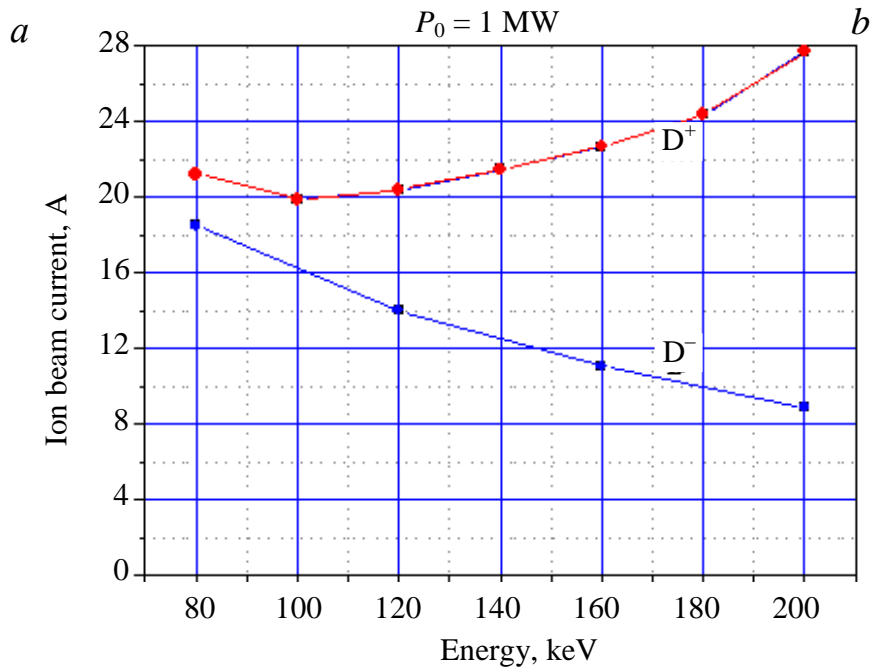

Fig. 3. Energy dependence of the power $(a)$ and current $(b)$ of source ion beams $\mathrm{D}^{+}$or $\mathrm{D}^{-}$required to obtain a $1 \mathrm{MW}$ neutral beam 
An example of the beam composition changes in $120 \mathrm{keV}$ PI and NI beams undergoing neutralization in a deuterium target is shown in Fig. 4. One can see that with positive ions being neutralized, the equilibrium yield of fast atoms is achieved in an «infinitely thick» target, while for negative ions there is a thickness optimum $\left(\tau_{\mathrm{opt}}\right)$ associated with a maximum atomic yield, and a further $\tau$ increase leads to the same yield as in the PI case. Accordingly, in the NI case, $\tau_{\text {opt }}$ is always taken, and for PI, in order not to let too much gas flow into the neutralizer, $\tau$ is usually chosen to ensure an atomic yield of $95 \%$ of the equilibrium value $\left(\tau_{0.95}, \Phi_{0.95}\right)$. In the 100 $200 \mathrm{keV}$ energy range, the $\tau_{\mathrm{opt}}$ value is practically independent on ion energy when using the NI technology, while in the case of PI, the $\tau_{0.95}$ dependence is quite strong (Fig. 5) and exceeds the optimal value for the NI technology $2-5$ times (100 to $200 \mathrm{keV}$, respectively).

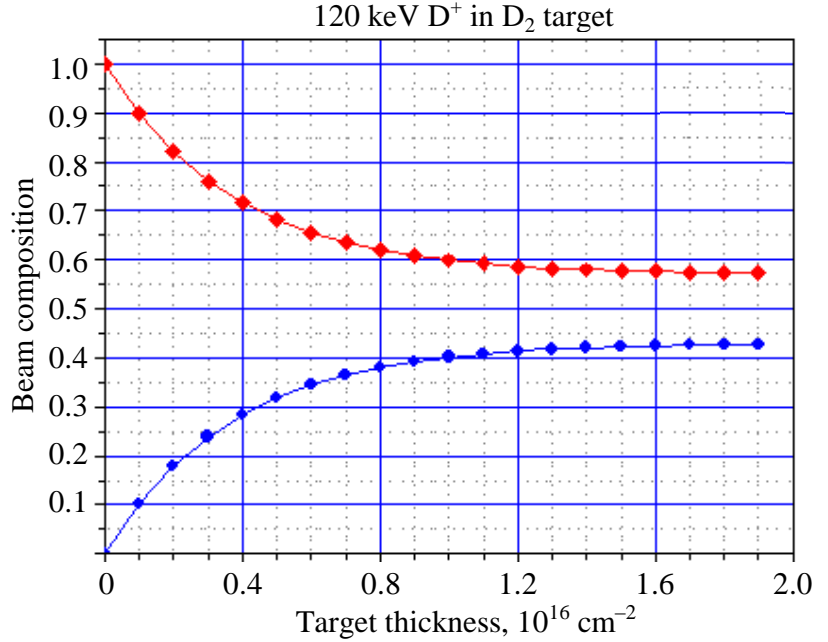

$a$

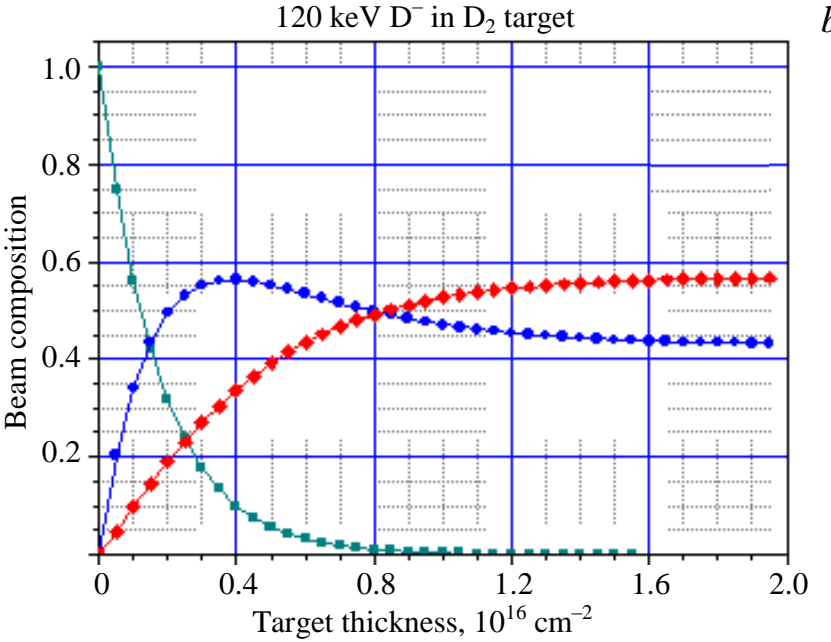

Fig. 4. Evolution of beam composition upon the passage of $\mathrm{D}^{+}(\bullet)(a)$ and $\mathrm{D}^{-}(\square)(b)$ ions of a $120 \mathrm{keV}$ energy through the $\mathrm{D}_{2}$ gas target, $\bullet-\mathrm{D}^{0}$

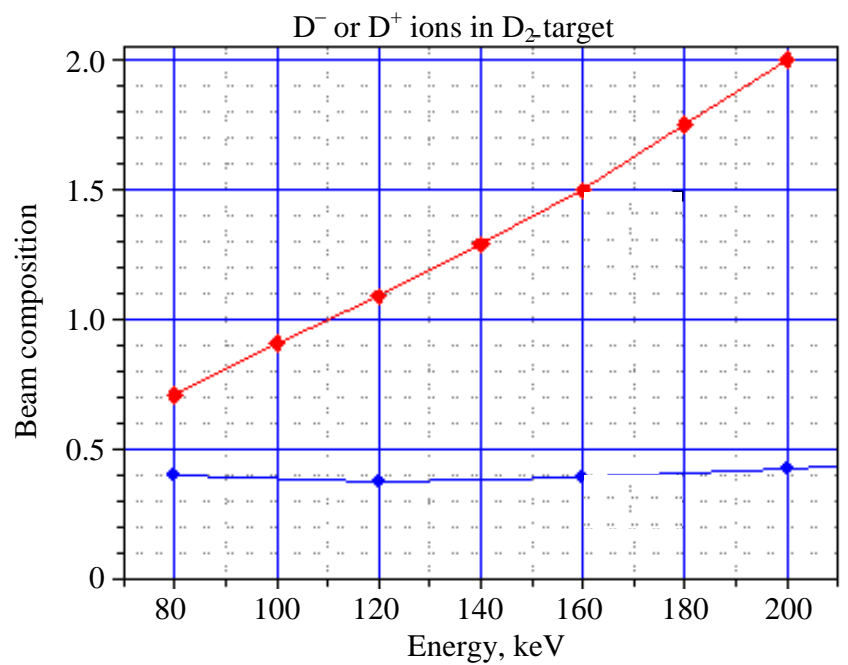

Fig. 5. Energy dependence of the required deuterium target thickness: optimal for the initial ion beam $\mathrm{D}^{-}$and $\tau_{0.95}$ for the $\mathrm{D}^{+}$beam: $\diamond-\mathrm{D}^{+} \rightarrow \mathrm{D}^{0}, \bullet-\mathrm{D}^{-} \rightarrow \mathrm{D}^{0}$

Thus, the above data point to the advantages of the NI technology, which become decisive at energies above $\sim 150 \mathrm{keV}$. The NI beam's small average divergence angle is an additional case in favor of the NI. For example, in ITER's NBI system, based on negative ion neutralizers, the beam divergence operating angle of $7 \mathrm{mrad}$ determines the high efficiency of beam transportation to plasma [5].

That said, the following NI weaknesses should be noted:

- about $15 \%$ of the NI current is contained in a «halo» with a divergence angle of up to $30 \mathrm{mrad}$, and more than a half of this current may be lost on the injector components, which increases power deposition along them and reduces the injector's power efficiency;

- $\mathrm{D}^{-}$ion current density is low $\left(20 \mathrm{~mA} / \mathrm{cm}^{2}\right.$ at the ion source exit); as a result, a current of several tens of amperes can only be obtained, if the plasma emission surface is uniform and measures more than $0.5 \mathrm{~m}^{2}$ in the gas-discharge chamber of the ion source;

- to date, for the nominal current density, a high degree of uniformity of the plasma emitter of an NI source with a large emission surface, which is necessary for the formation of a beam with a low angular divergence, has yet to be demonstrated;

- to reduce the losses of NI inside the ion-optical system (IOS) of the ion source (IS) owing to their stripping on the background gas, a vacuum gap is provided between the IS and the neutralizer to evacuate the gas; as a result, gas feeding into the neutralizer increases several times due to its outflow in both directions.

The PI technology (for ion energies less than $150 \mathrm{keV}$ ) has the following strengths: 
— an order of magnitude higher $\mathrm{D}^{+}$current density is achieved at the PI source exit, allowing the area of the uniform plasma emitter and electrodes of the IS IOS to be reduced approximately 3-4 times even if the PI current is twice as large as that required. At the same time, the neutralizer dimensions are decreased, and the flow of gas fed to the neutralizer and needed to achieve required target thickness is reduced;

- in addition, in the PI scheme, the neutralizer is attached to the ion source and gas exiting the source participates in the creation of the target, making the gas load on the injector's cryogenic pumping system appreciably less than with the NI technology;

- PI-based beam injectors are compact and extensively tested in different fusion machines.

The PI technology disadvantages include:

- an approximately twice as wide divergence angle compared with the NI technology, the result being a weaker beam transmission efficiency;

- presence of $\mathrm{D}_{2}^{+}$and $\mathrm{D}_{3}^{+}$molecular ions (15-20\% and 7-10\%, respectively) in the IS beam, from which atoms with energies $E / 2$ and $E / 3$ originate in the neutralizer as a result of dissociation and neutralization. Ionized and captured at the tokamak plasma periphery, these atoms contribute little to the in-plasma current generation;

— the system of magnetic deflection of residual ions exiting the neutralizer must have a large size beam receiver to ensure the interception of ions with three energy fractions;

- because the residual ion beam power can be $\sim 1.5$ times greater than the NB power (see Fig. $3, a$ ), this receiver appears to be the most energy-stressed component of the injector.

The analysis of an injected NB ionization in the FNS-ST plasma and in-plasma current generation is discussed in [6]. It is shown that in a small-sized FNS-ST with a plasma concentration of $\sim 1 \cdot 10^{20} \mathrm{~m}^{-3}$, up to $5 \%$ of delivered NB power passes through the plasma if particle energy is higher than $\sim 150 \mathrm{keV}$. Such a load on the FNS-ST chamber wall is regarded as critical, and the upper acceptable NB energy level is estimated at $140 \mathrm{keV}$.

Setup and parameters of the $\mathbf{D}^{+}$ion-based FNS-ST injector. A FNS-ST injection module configuration allowing the delivery of a $3.5 \mathrm{MW}$ deuterium atomic beam power is considered with a view of using a PI source with a deuterium ion energy in the range of $100-140 \mathrm{keV}$. A $3.5 \mathrm{MW}$ power should ensure the tokamak operation during the injection of a $10 \mathrm{MW}$ NB using four alternately enabled injectors, of which three are in operation, and one is in the cryopump regeneration mode (or setting, preparation, etc.). The IS geometry and parameters, as well as the components of the beam path from the IS output electrode to the tokamak chamber entrance window are specified. The injector schematic is shown in Fig. 6.

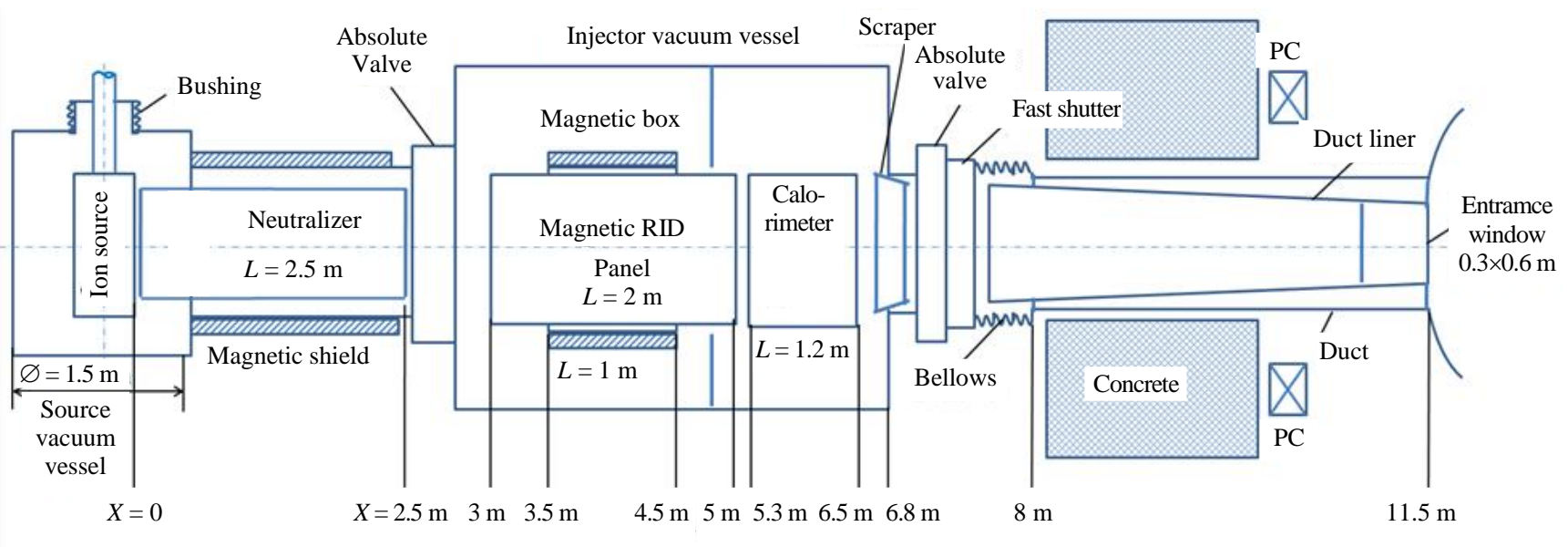

Fig. 6. Schematic diagram of the positive deuterium ions-based injection module for the FNS-ST tokamak

Injector main components. An ion source producing a positive deuterium ion beam with a 80 A current. A vertically elongated uniform plasma emitter of ions with emission current density $=0.2 \mathrm{~A} / \mathrm{cm}^{2}$ on an area of $18 \times 115 \mathrm{~cm}$ is formed in the gas-discharge chamber (GDC). An ion beam with a divergence angle of $\pm 15 \mathrm{mrad}$ is extracted from the plasma and shaped using a four-electrode multi-aperture IOS. Each electrode has five sections, each containing $8 \times 10$ profiled apertures, so that each section produces 80 elementary beams («beamlets»), whose axes are focused horizontally on the center of the tokamak entrance window. With their axes separated 
by $220 \mathrm{~mm}$, these sections are inclined vertically, so that their center lines are also directed at the center of the entrance window. To ensure a stationary operation, the electrodes have channels in their bodies, intended for forced water cooling. The IS is placed inside a source vacuum vessel (SVV) $1.5 \mathrm{~m}$ in diameter and $2.2 \mathrm{~m}$ high. All IS communications kept at high potential (e.g., the GDC, emission and extracting electrodes) are admitted into the SVV through a ceramic bushing $0.5 \mathrm{~m}$ in diameter and $0.4 \mathrm{~m}$ high.

The neutralizer is a $2.5 \mathrm{~m}$ long water-cooled copper liner with a $18 \times 120 \mathrm{~cm}$ passage window, installed inside the tube connecting the SVV with the injector's vacuum vessel (VV). The gas target is formed by a deuterium flow injected into the liner near the IS, whose flow rate is adjusted with regard to the gas flow from the source GDC. A magnetic shield, fixed on the connecting tube, is designed to reduce the tokamak's scattered magnetic field inside the neutralizer to within $1 \mathrm{G}$. The front end of the liner is inserted into the SVV close to the IOS output (grounded) electrode (the «adjusted» neutralizer).

An absolute vacuum valve is at the entrance of the injector VV, it separates the SVV and the rest of the beam path by vacuum when the SVV needs to be opened for repair or IS replacement.

The injector VV contains: a magnet to deflect residual positive ions leaving the neutralizer onto a residual ion dump, a movable diagnostic NB calorimeter, and cryosorption pumps with a $1 \cdot 10^{6} \mathrm{l} / \mathrm{s}$ pumping speed. The VV is $2 \times 2.5 \times 4 \mathrm{~m}(W \times H \times L)$, with panels of cryopumps fixed on its side walls.

Magnetic system for residual ion deflecting and dumping (MRID). A post neutralizer beam consists of NB and residual ions, whose power significantly exceeds the NB power, and on-axis power density (PD) reaches 70 $80 \mathrm{MW} / \mathrm{m}^{2}$. To ensure a stationary reception of such a PD, the residual ion beam must strike the dump surface at a less than $10^{\circ}$ angle, meaning that a large space within the injector VV should be provided for dumping the residual ions - especially with account of components with energies $E / 2$ and $E / 3$. Therefore, here we consider a small-sized version, in which ions are horizontally deflected by a vertical magnetic field (MF) onto a dump panel built into the magnetic deflection system. A schematic view of the magnetic system, in which the MF horizontal profile is uniform inside the deflecting volume, is shown in Fig. 7, $a$, and a photo of the experimental device is given in Fig. 7, $b$.
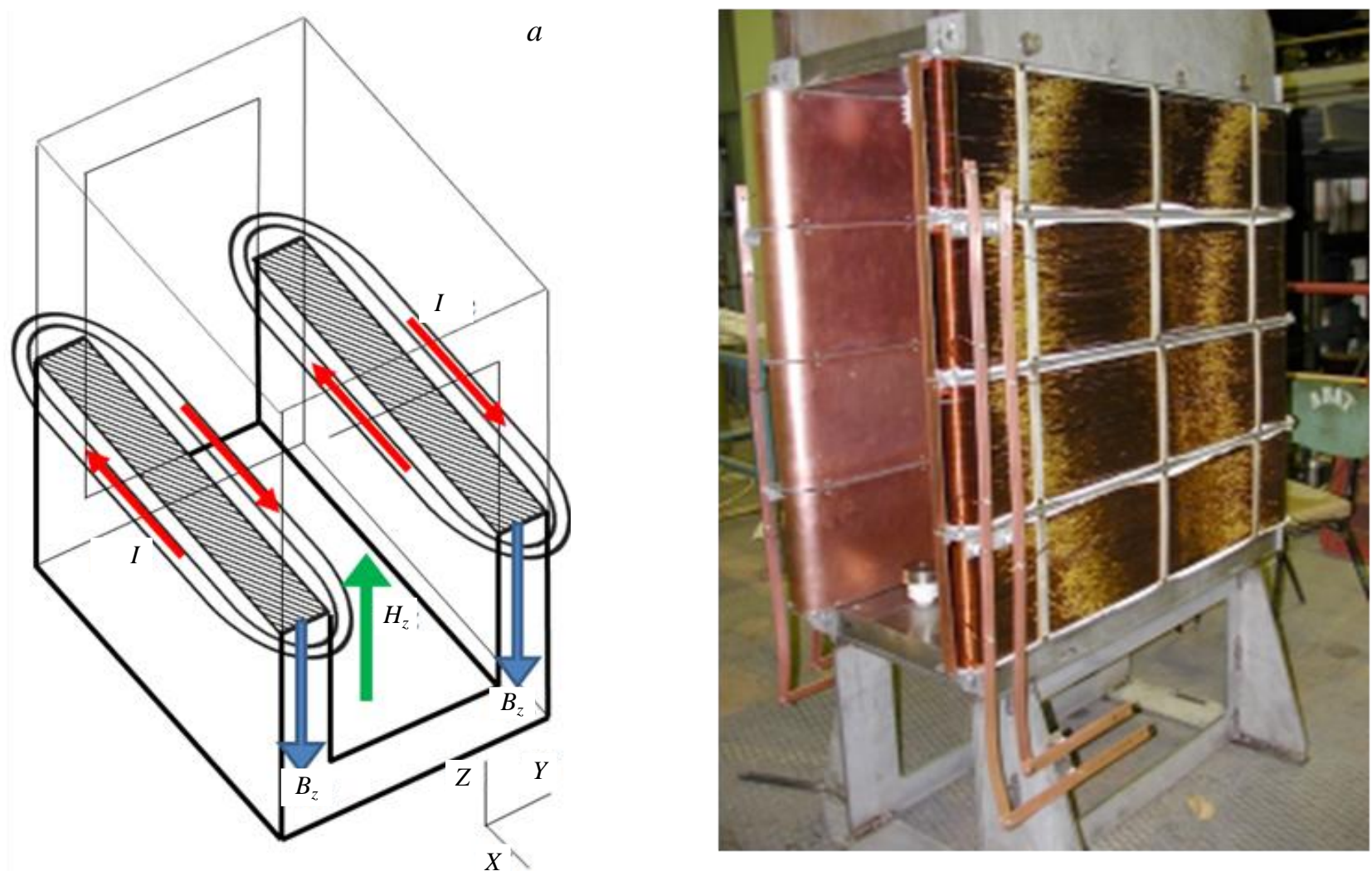

Fig. 7. Schematic view of the magnetic system ( $I-$ magnetic coil current) $(a)$ and a photo of the experimental device $(b)$, whose «magnetic steel box» has a length of $1 \mathrm{~m}$, an opening of $0.4 \times 1 \mathrm{~m}$ and a magnetic steel thickness of $6 \mathrm{~mm}$

The magnet system is a «magnetic steel box» whose side walls (cores) carry coils, which allow identically directed current to be distributed over a height of $1 \mathrm{~m}$. A MF created inside the box is in opposition to induction $B_{\mathrm{Z}}$ of the steel cores. Fig. 8 shows the measured profiles of the vertical MF inside and outside the experimental 
device (in the local coordinate system) at currents of $115 \mathrm{~A}$ in each coil. Inside the «box», the field horizontal uniformity is acceptable, but along the MF system axis it falls more than 10 times at a distance of about $1 \mathrm{~m}$ from the «box» edge.
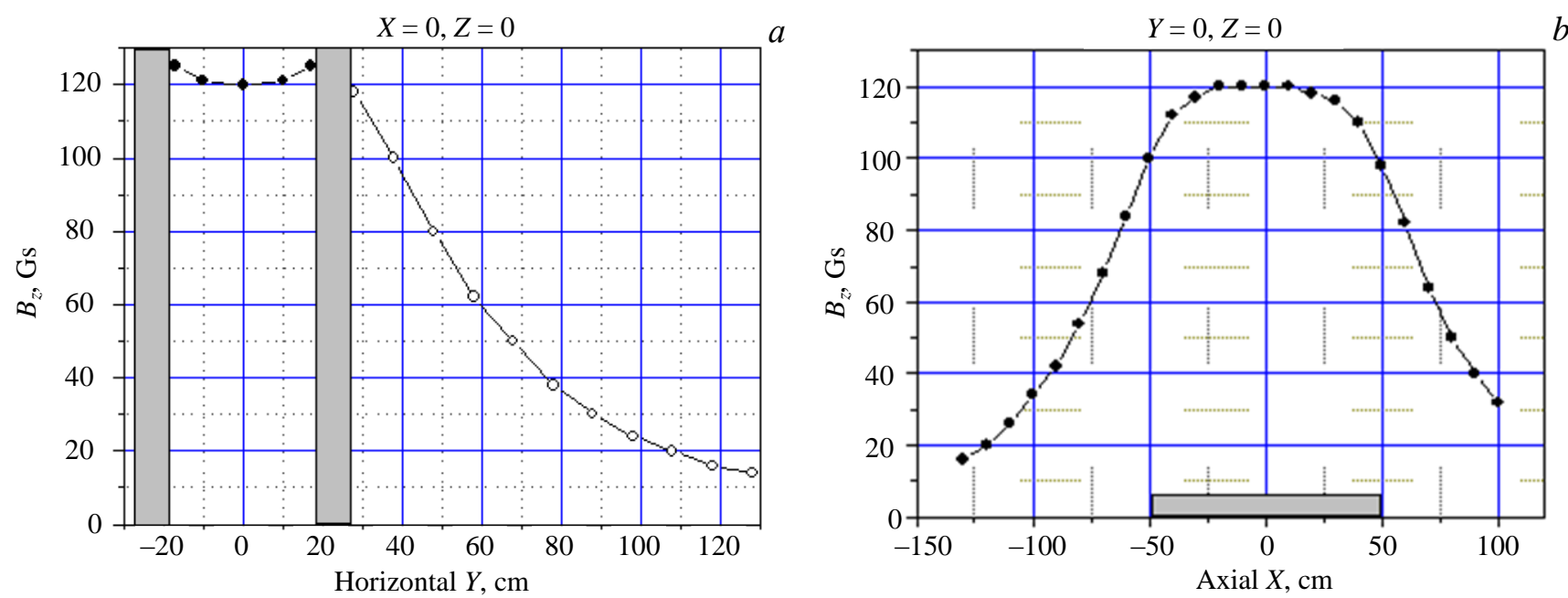

Fig. 8. Experimental profiles of the vertical magnetic field along the horizontal $(a)$ and axial $(b)$ coordinates of the MRID (in the local coordinate system) at current of $115 \mathrm{~A}$ in each of the coils

The vertical panel collecting the residual ions is placed inside the deflection system (Fig. 9). It consists of two layers of horizontal tubes made of hardened chromium-zirconium bronze with swirl heat removal intensifiers (swirl tube elements STEs, similar to the dumps of the ITER injectors) [5]. The STEs are of $20 \mathrm{~mm}$ in outer diameter and have $2 \mathrm{~mm}$-thick walls. They remove heat loads with heat flux densities up to $\sim 10 \mathrm{MW} / \mathrm{m}^{2}$ when a water velocity in one STE is $2 \mathrm{~m} / \mathrm{s}$ and up to $15 \mathrm{MW} / \mathrm{m}^{2}$ with the velocity of $3.5 \mathrm{~m} / \mathrm{s}$ is provided [7]. In each layer, the pitch between the tube axes is $34 \mathrm{~mm}$, the tubes of the back layer are shifted relative to the front layer by half pitch, providing full interception of the beam even in a case of mutual vertical displacement of the tubes by $\sim 2 \mathrm{~mm}$. There are altogether 65 tubes, each with a working length of $2 \mathrm{~m}$.

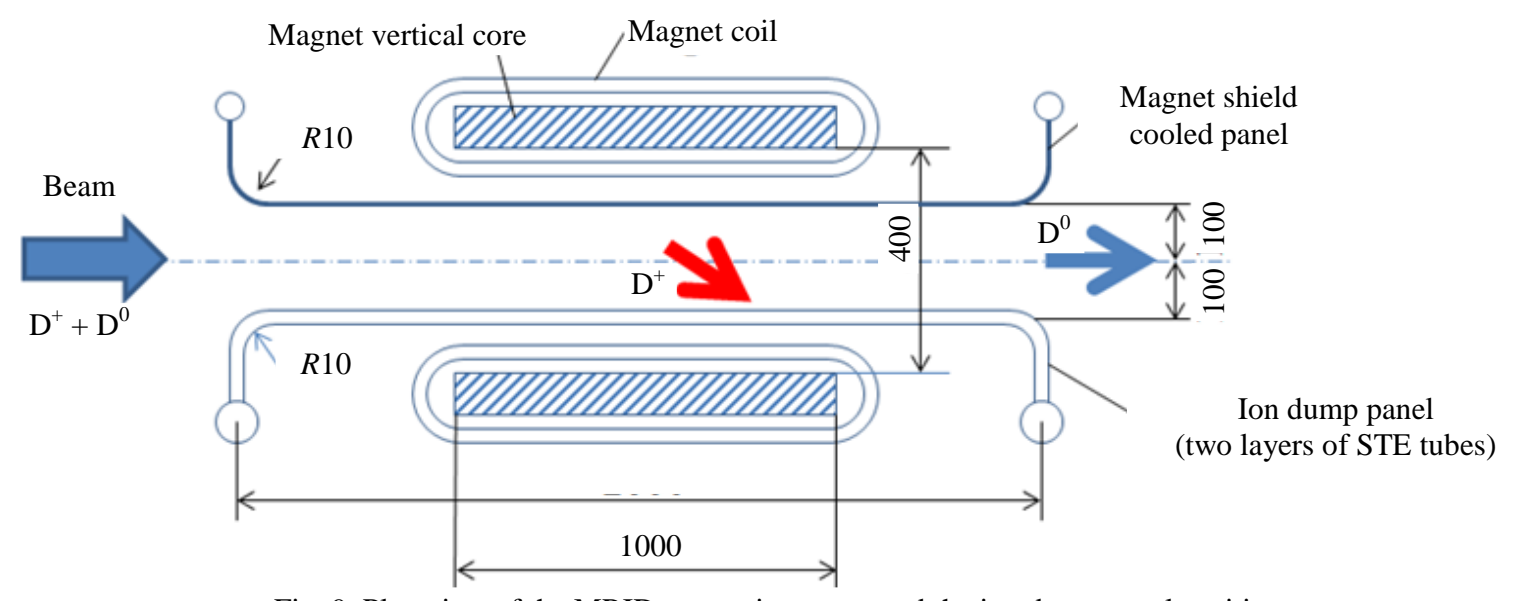

Fig. 9. Plan view of the MRID magnetic system and the ion dump panel position

The calorimeter is a device unit for receiving NB during training of an ion source and bringing its parameters to the operating mode during the period when this injector does not inject NB into the tokamak. It is equipped with diagnostic devices for measuring the NB power and the beam profile over its cross section to determine its divergence and sight accuracy. The calorimeter consists of two movable panels, which for this period move, forming a V-shaped configuration with an opening angle of $20^{\circ}$, which provides a decrease in the peak PD on the panels by about 5 times. Each panel, similarly to the MRID, consists of two layers of chrome-zirconium bronze tubes, the only difference is in the working length of the tubes - in the calorimeter it is $1.2 \mathrm{~m}$, the number of tubes in each panel is 65 . The panels open when the injector operates on the tokamak, the width of the corridor between the panels is $0.4 \mathrm{~m}$.

Other units along the injection path are:

- scraper in the form of a truncated pyramid $(6.7<X<7.1 \mathrm{~m})$, designed to cut off the beam «wings» to reduce the load on the elements of the connecting duct line; 
— absolute vacuum valve that cuts off the injector from the tokamak during work with opening the volumes of either the injector or the tokamak;

- fast shutter that only opens up when the NB is injected into the plasma. In the closed state, it has insignificant gas conductivity both from the injector to the tokamak and vice versa, and provides a small leakage of gas into the tokamak chamber while the cryopanels are being regenerated in the injector VV;

- bellows connecting unit, designed to compensate the injector and the tokamak's thermo-mechanical displacements relative to one another, when the system is in operation;

- NB duct with a water-cooled liner inside that takes on the neutrals not passing into the tokamak entrance window, as well as ions formed along the path due to re-ionization of beam atoms in collisions with background gas molecules and deflected to the liner walls by the tokamak stray magnetic field.

Efficiency of the NB transport and power loads onto the beam path components. Calculations were carried out using the PDP and BTR beam codes (see [8] for details). Data on the geometry of the injection path and the beam parameters were obtained from a series of optimization calculations using the following criteria: NB power delivered to the plasma: $3.5 \mathrm{MW}$, loads on the components along the beam path have power density within $500 \mathrm{~kW} / \mathrm{m}^{2}$, and for dumps of NB and residual ions not more than $15 \mathrm{MW} / \mathrm{m}^{2}$.

As mentioned above, the IS output electrode has five sections, arranged vertically and inclined in such a way that their centerlines are directed at the center of the tokamak window. They are distanced $11.5 \mathrm{~m}$ away from the IS output electrode. Each section has $8 \times 10$ apertures, from which beamlets are extracted and focused horizontally at $11 \mathrm{~m}$. The source produces a vertically elongated narrow beam with an initial size of $15 \times 110 \mathrm{~cm}$, this configuration was chosen to minimize the beam width in the region of the tokamak entrance window and in the plasma. In addition, the minimum gas inflow into the neutralizer is achieved, since its conductivity is proportional to the square of its liner width.

The deuterium ion beam current is $80 \mathrm{~A}$ at a current density on the plasma emission surface in the GDC of $0.2 \mathrm{~A} / \mathrm{cm}^{2}$. With such the current density, the composition of the beam ions is approximately $\mathrm{D}^{+}: \mathrm{D}_{2}^{+}: \mathrm{D}_{3}^{+}=$ $=0.75: 0.15: 0.10$. The thickness of the deuterium target in the neutralizer appears to be sufficient to dissociate molecular ions almost entirely. For originating ions and atoms with energies $(E / 2$ or $E / 3)$, the efficiency of their neutralization is determined in accordance with the dependence shown in Fig. 1. The composition of the mixed beam at the exit from the neutralizer is given in Table 1. It can be seen that in comparison with Fig. 1, the average efficiency of neutralization of the initial ion beam increases due to the appearance of particles with energies $E / 2$ and $E / 3$ due the dissociation of molecular ions.

$\mathrm{T}$ a b 1 e 1 . Beam composition at the neutralizer exit, at a 80 A source ion current, with $\mathrm{D}^{+}, \mathrm{D}_{2}^{+}$and $\mathrm{D}_{3}^{+}$being in the 0.75:0.15:0.10 ratio, and ion current components in the 60:12:8 A ratio

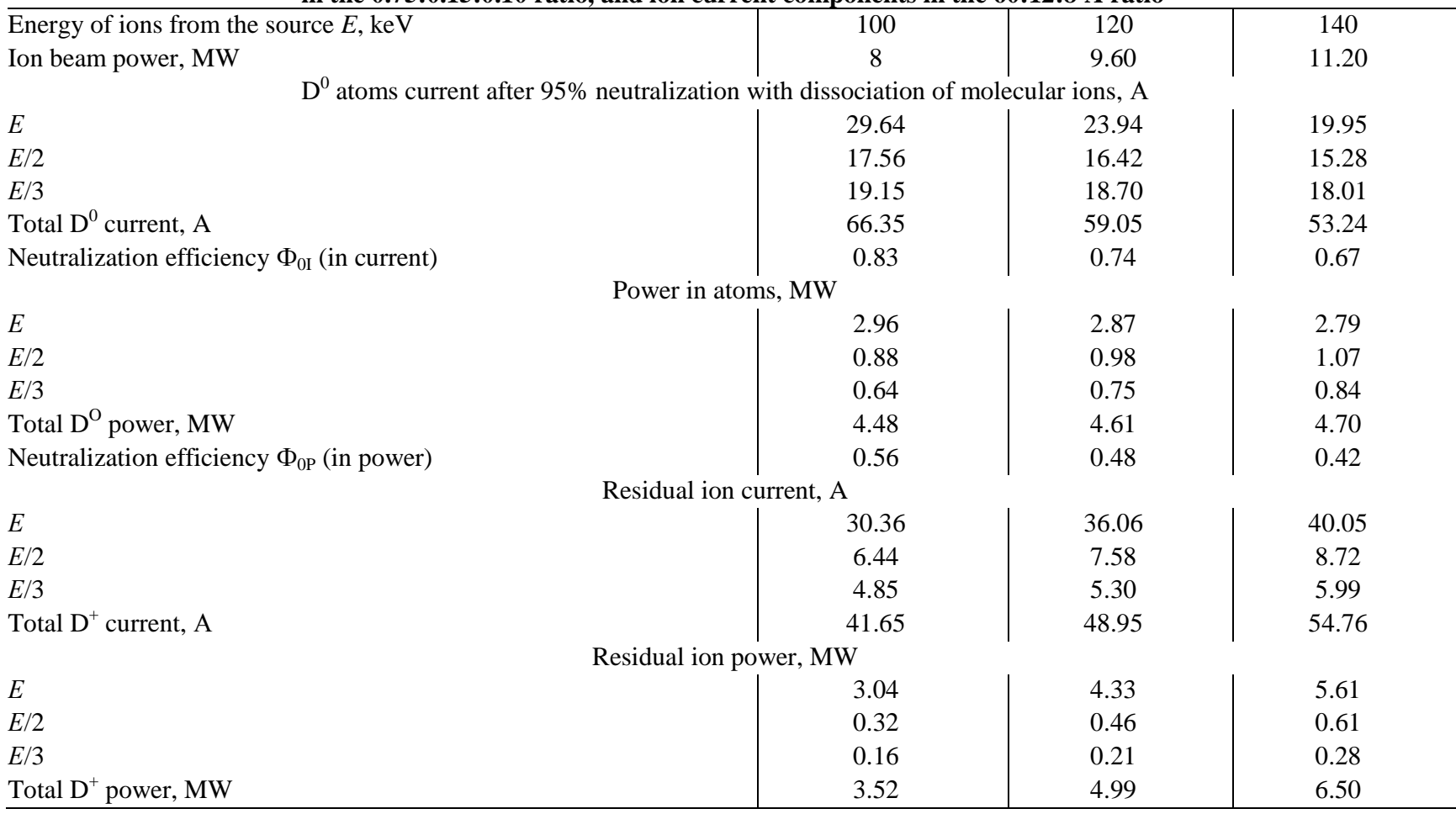


Calculations of the beam transport and loads on the beam path components were carried out for a $140 \mathrm{keV}$ $\mathrm{D}^{+}$ion beam energy extracted from the IS. The beam geometry on the path from the IS exit to the MRID exit and the cross-section of the mixed beam at the neutralizer exit with a maximum PD of $140 \mathrm{MW} / \mathrm{m}^{2}$ are shown in Fig. 10.
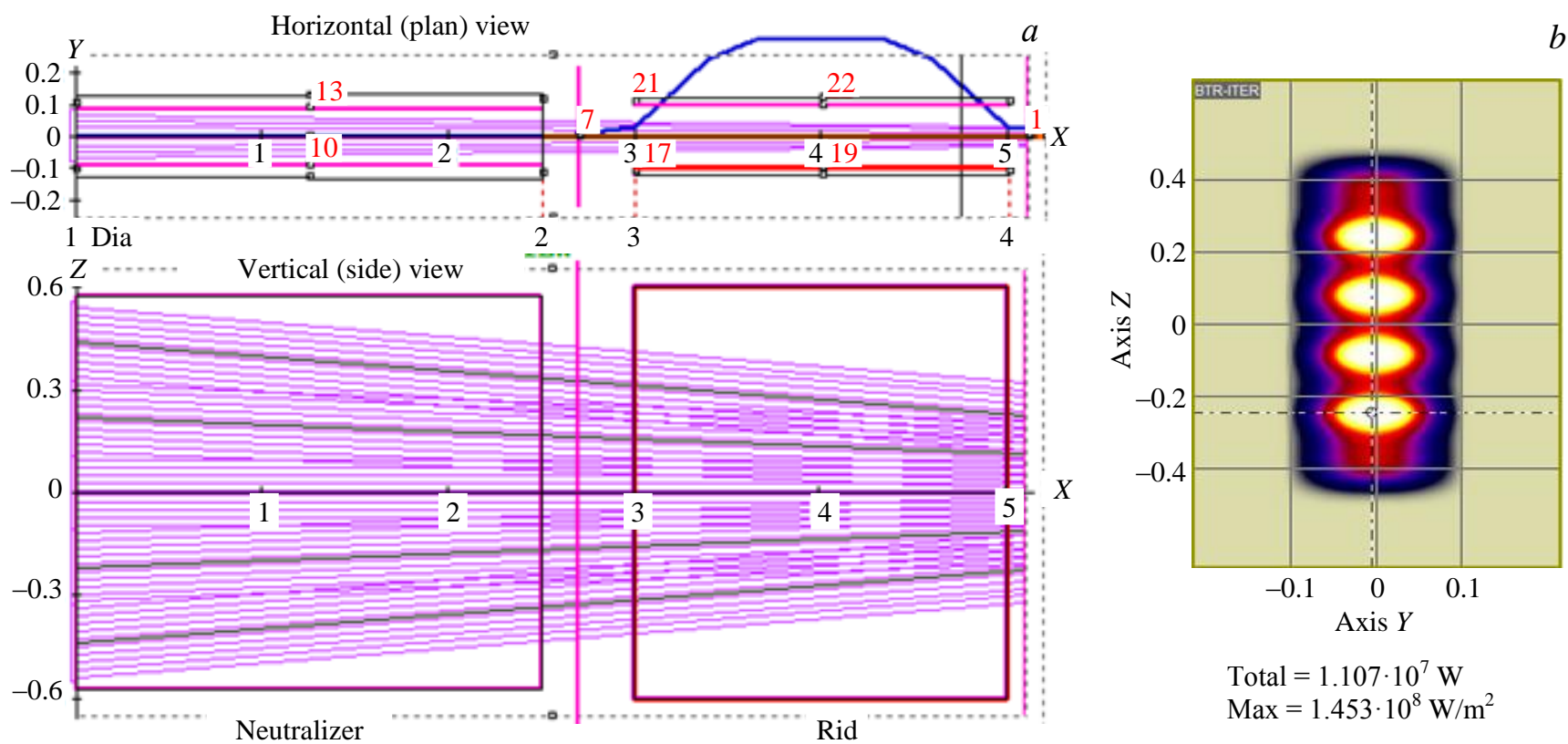

Total $=1.107 \cdot 10^{7} \mathrm{~W}$ $\operatorname{Max}=1.453 \cdot 10^{8} \mathrm{~W} / \mathrm{m}^{2}$

Fig. 10. Beam geometry in the path from the IS exit to the MRID exit. The axial lines of the output electrode sections and beamlets are shown, the right (№ 10) and left (13) walls of the neutralizer, the residual ions dump panel (19) and the screen plate (22) of the MRID, the axial profile of the model magnetic field are marked $(a)$. Section of the beam at the exit from the neutralizer at a beam energy of $140 \mathrm{keV}$ and an average angle of divergence $\theta_{b}= \pm 15 \mathrm{mrad}(b)$

Neutralizer loads. Loads coming from the beam on the neutralizer side walls depend on the accuracy of the IS beam axis horizontal angular alignment relative to the injection axis. Calculation result for an ideal setting is shown in Fig. 11: PD peaks at the neutralizer exit, and four peaks emerge vertically due to the overlapping of beams starting from adjacent sections of the IS electrodes.
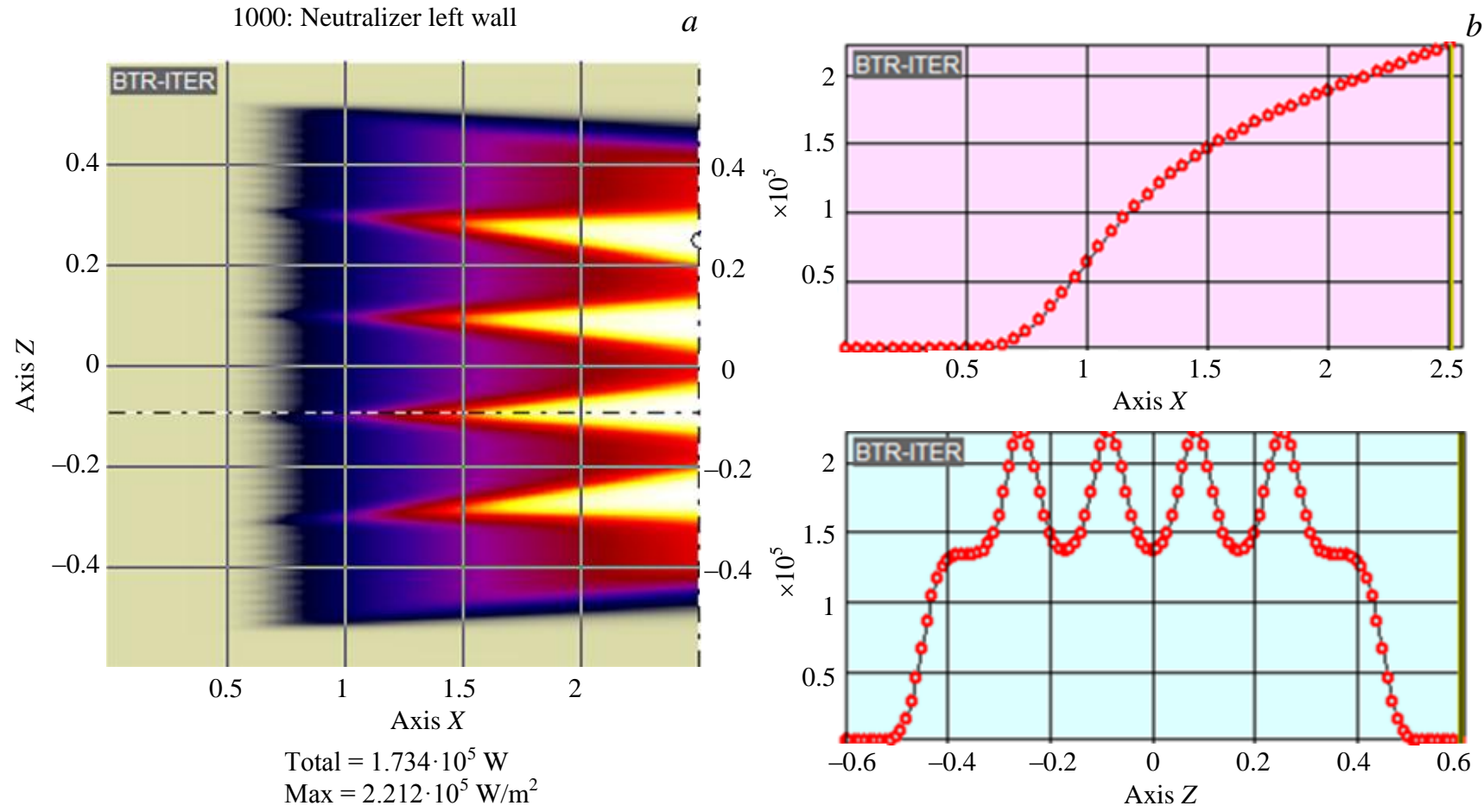

Fig. 11. Load coming from the beam on the neutralizer left wall with the beam axis ideally fixed between the IS and injection path axis: beam footprint $(a)$, axial and vertical power density profiles (at $X=2.5 \mathrm{~m})(b)$ 


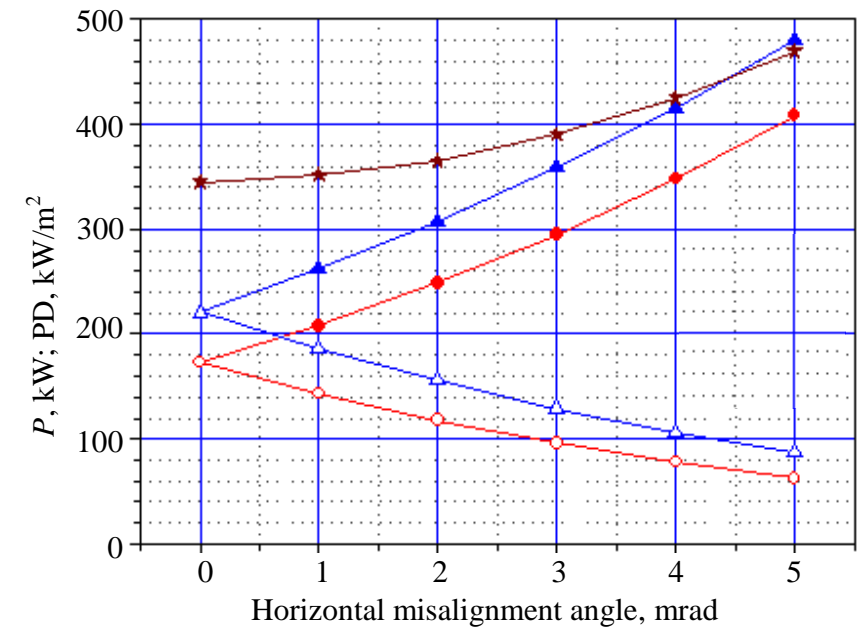

Fig. 12. Power $(P)$, maximum PD and total power $\left(P_{\text {tot }}\right)$ on the neutralizer right and left walls as functions of the misalignment angle in the beam axis setting: $\diamond-P$ left, $\diamond-P$ right, $\Delta-\mathrm{PD}$ left, $\Delta-\mathrm{PD}$ right, $\star-P$ tot

beam footprint, and axial and vertical PD profiles on the panel are shown in Fig. 13.

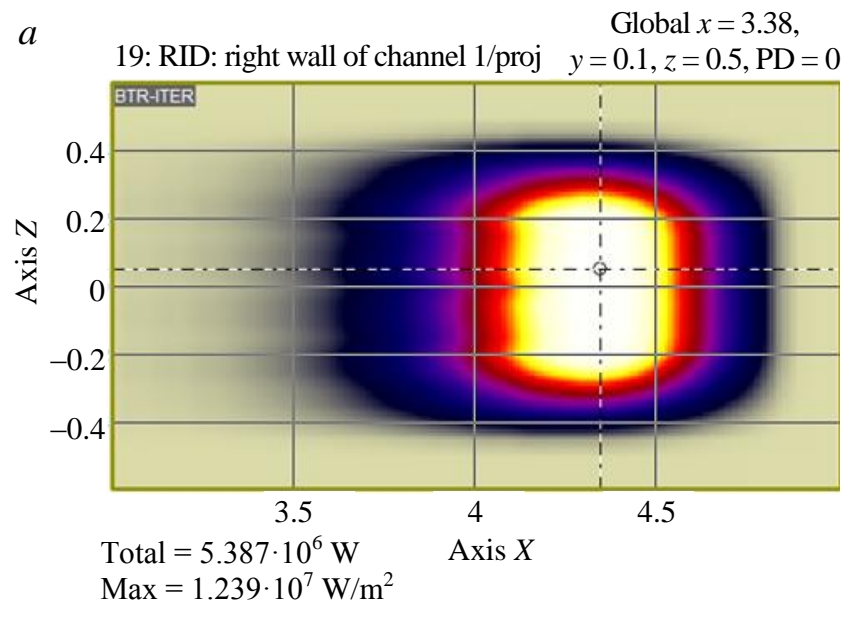

$\times 10^{7}$

$\begin{array}{llllllllll}0 & 0.12 & 0.25 & 0.37 & 0.50 & 0.62 & 0.74 & 0.87 & 0.99 & 1.11\end{array}$

Fig. 13. Footprint of the deflected beam of $140 \mathrm{keV}$ residual $\mathrm{D}^{+}$ions on the MRID dump panel $(a)$, and power density axial and vertical profiles $(b)$

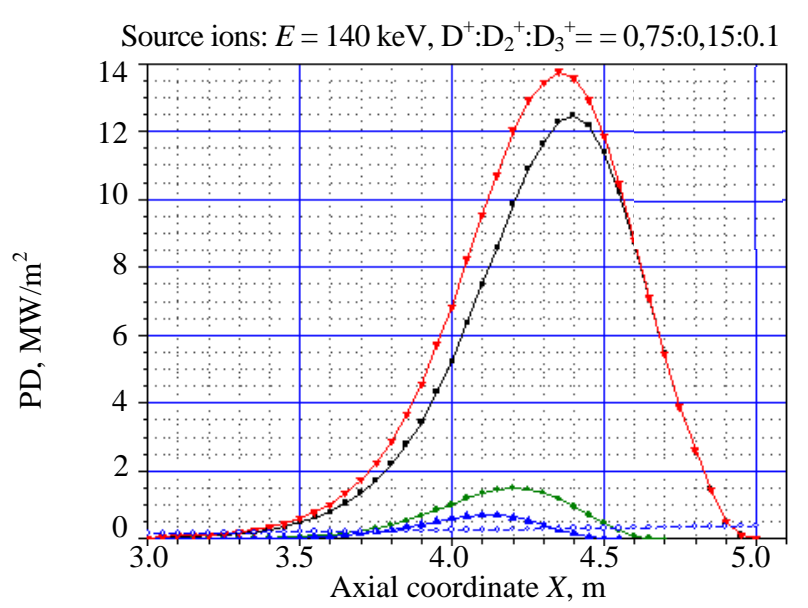

Fig. 14. PD axial profiles on the MRID dump panel of the residual ion beam components with energies of 140,70 , and $46.7 \mathrm{keV}$, deflected by a 130 Gs magnetic field; the total PD profile; and load profile from the NB for the case of the ion beam axis angular misalignment, $\alpha_{\mathrm{h}}=-4 \mathrm{mrad}$ (to the right), $E, \mathrm{keV}:-140, \bullet-$ $70, \wedge-46, \nabla-$ sum PD, 。- NB PD
An appreciable load asymmetry can be observed on the right and the left walls, even with relatively small misalignment angles resulting from a horizontal beam axis adjustment $\left(\alpha_{h}\right)$ and likely due to inaccuracies both in the IOS electrodes assembly and the IS installation in the SVV (Fig. 12).

As can be seen from the figure, the ratio of both powers and $\mathrm{PD}$ on the left/right sides grows 4-fold already at $\alpha_{\mathrm{h}}=4 \mathrm{mrad}, P_{1}$ reaches $350 \mathrm{~kW}$, and $\mathrm{PD}_{1}$ is more than $400 \mathrm{~kW} / \mathrm{m}^{2}$, while the total beam power losses in the neutralizer increases almost by $25 \%$ to $425 \mathrm{~kW}$. It should be noted that the ratio of loads on the neutralizer walls can serve as a good diagnostic tool for determining $\alpha_{\mathrm{h}}$ when tuning the injector.

MRID loads. To completely intercept the beam of residual $\mathrm{D}^{+}$ions with energy $E=140 \mathrm{keV}$ on the MRID receiving panel (19 in Fig. 10), a deflecting vertical magnetic field of $130 \mathrm{Gs}$ is required. The

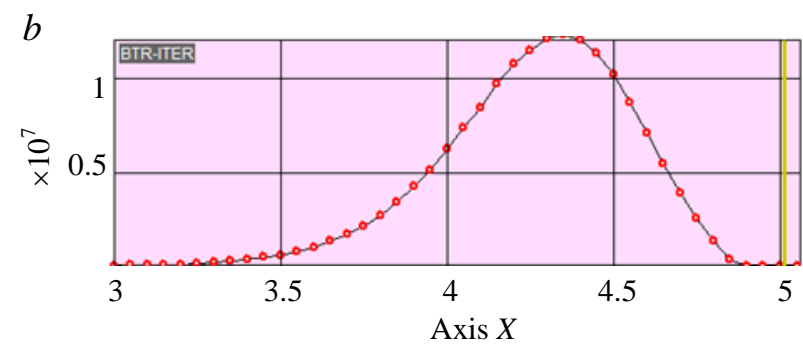

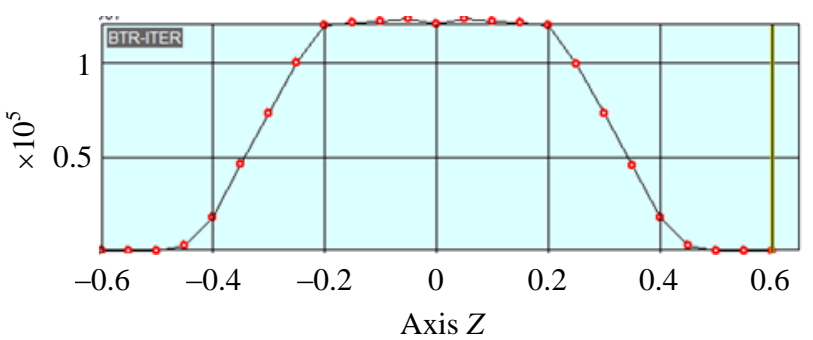

Beams of residual $\mathrm{D}^{+}$ions with energies $E / 2(70 \mathrm{keV})$ and $E / 3(\sim 47 \mathrm{keV})$ are dumped onto the same panel with small shifts and with significantly lower PD. The total PD reaches a value close to $14 \mathrm{MW} / \mathrm{m}^{2}$ (Fig. 14).

The calorimeter load. The calorimeter operates when it is necessary to get the IS into working order and check the adjustment of the beam parameters. During this period its panels are shifted, forming a $\mathrm{V}$-shape configuration. The junction of the panels is at $X=6.5 \mathrm{~m}$. With an ideal beam axis setting, the PD profiles on the right and the left panels are symmetrical. The calorimeter receives a neutral beam with three atomic components energies $E, E / 2$ and $E / 3$, the footprints of which are superimposed 
on each other. Fig. 15 shows the footprint, and axial and vertical profiles of the NB on the left panel at the energy $E=140 \mathrm{keV}$ of $\mathrm{D}^{+}$ions from the source and a beam axis ideally aligned to the injection axis. The power of $\sim 2.2 \mathrm{MW}$ received by the panel is half the NB power with a PD up to $\sim 10 \mathrm{MW} / \mathrm{m}^{2}$.

$a$

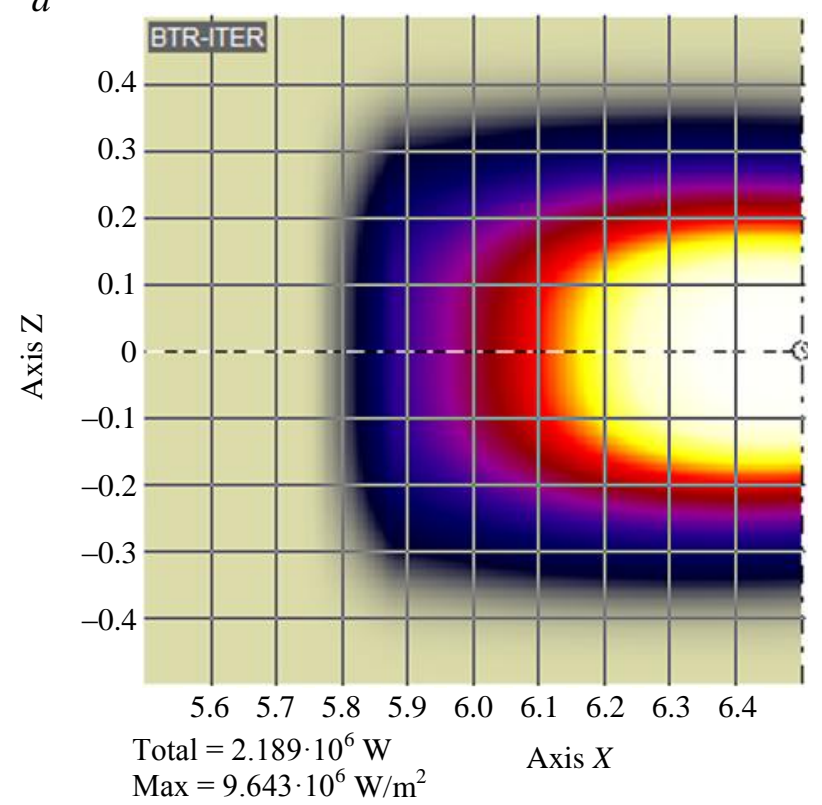

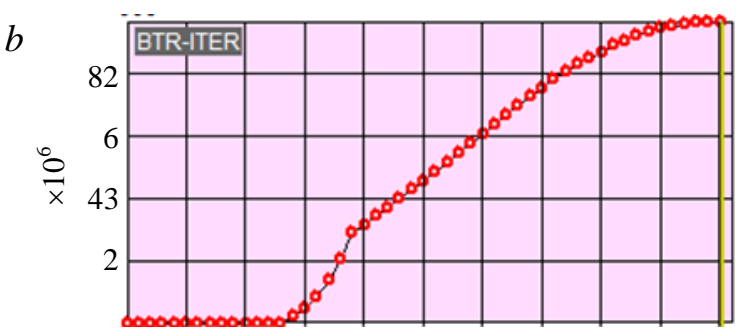

Axis $X$

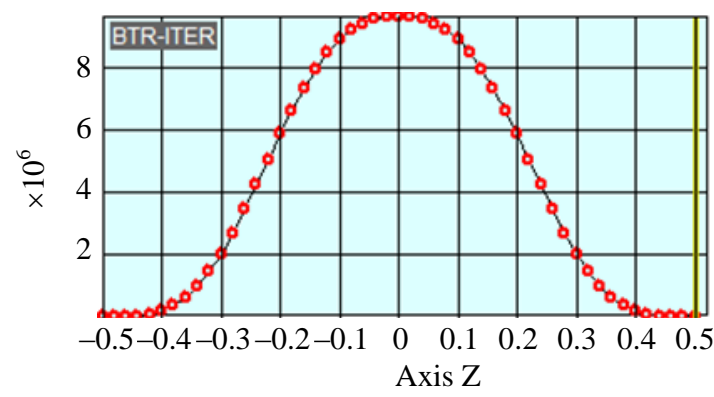

Fig. 15. Footprint of the neutral beam on the calorimeter left panel $(a)$, and beam power density axial and vertical profiles $(b)$ at the energy of $\mathrm{D}^{+}$ions from the source, $E=140 \mathrm{keV}$

Scraper loads. The scraper geometry should provide a NB «cutoff» to prevent the PD loads coming from the beam on the walls of the NB duct liner and the scraper itself from exceeding $\sim 500 \mathrm{~kW} / \mathrm{m}^{2}$. This requirement has to do with the technological difficulties of cooling the walls. Maximum permissible misalignment angles resulting from horizontal and vertical beam axis adjustment, $\alpha_{\mathrm{h}}$ and $\alpha_{\mathrm{v}}$, were calculated as \pm 4 and $\pm 6 \mathrm{mrad}$, respectively, relative to the injection axis. This allowed appropriate configuration of these components to be selected. Figs 16, 17 shows the scraper dimensions and the maximum power and PD profiles of the loads on its left and bottom walls.

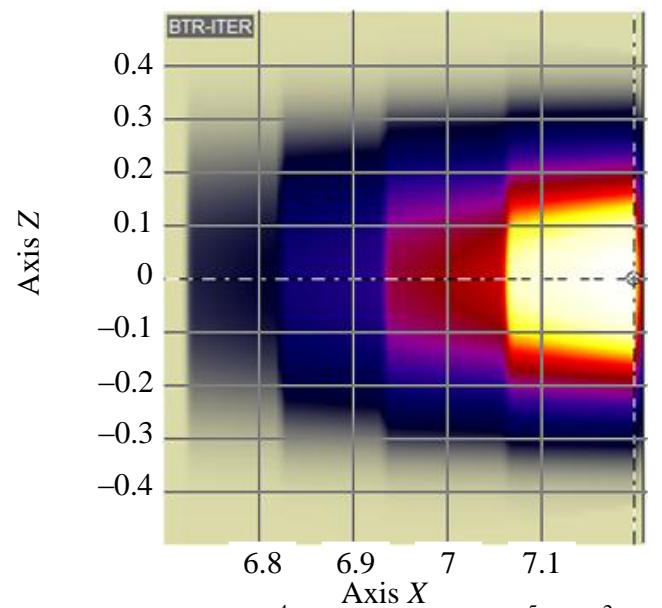

Total $=5.154 \cdot 10^{4} \mathrm{~W}, \operatorname{Max}=5.248 \cdot 10^{5} \mathrm{~W} / \mathrm{m}^{2}$

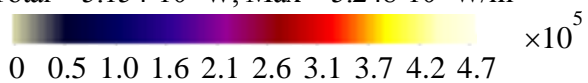

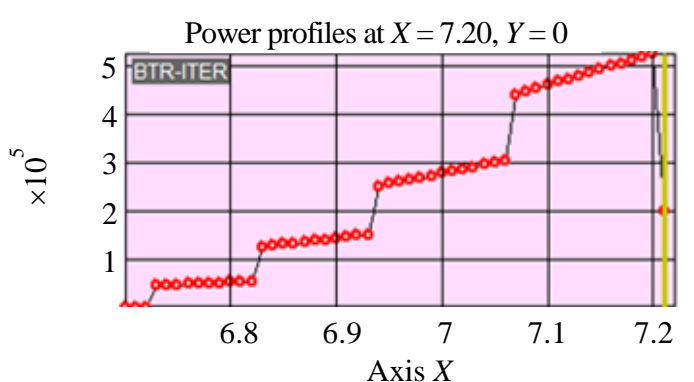

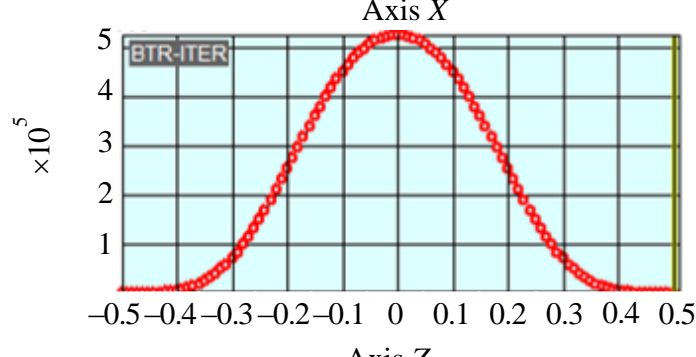

Axis $Z$

Fig. 16. Scraper dimensions $\left(X_{8}=6.7 \mathrm{~m}, W / H=0.32 / 1.0 \mathrm{~m} ; X_{9}=7.2 \mathrm{~m}, W / H=0.28 / 0.8 \mathrm{~m}\right)$ and maximum power loads and $\mathrm{PD}, \alpha_{\mathrm{h}} / \alpha_{\mathrm{v}}=4 / 0 \mathrm{mrad}$ 


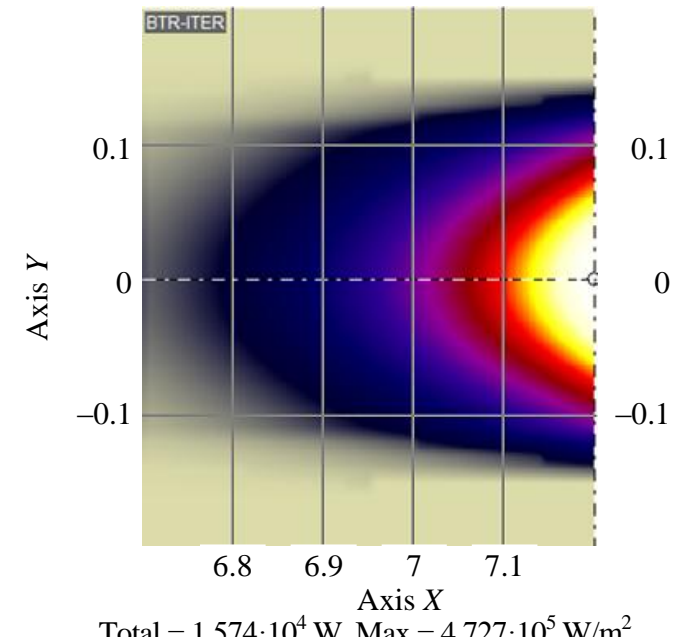

Total $=1.574 \cdot 10^{4} \mathrm{~W}, \mathrm{Max}=4.727 \cdot 10^{5} \mathrm{~W} / \mathrm{m}^{2}$

$0 \begin{array}{llll}0.5 & 0.91 .41 .92 .42 .83333 .84 .3 \times 10^{5}\end{array}$

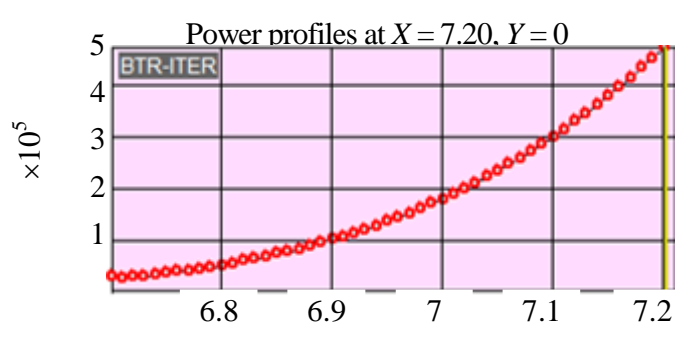

Axis $X$

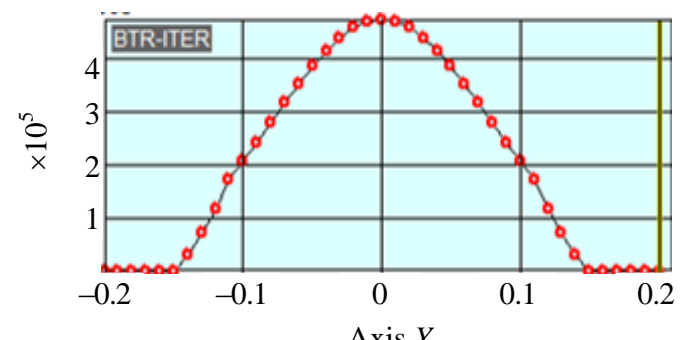

Axis $Y$

Fig. 17. Scraper dimensions $\left(X_{8}=6.7 \mathrm{~m}, W / H=0.32 / 1.0 \mathrm{~m} ; X_{9}=7.2 \mathrm{~m}, W / H=0.28 / 0.8 \mathrm{~m}\right)$ and maximum power loads and PD profiles and bottom, $\alpha_{\mathrm{h}} / \alpha_{\mathrm{v}}=0 /-6 \mathrm{mrad}$ walls of the scraper at the maximum permissible misalignment angles of the beam axis relative to the injection axis

NB duct liner loads. The liner is divided into two sections, and has a constant channel width of $0.3 \mathrm{~m}$ along its entire length, while the sections' upper and lower walls have different slopes to equalize PD peak values, as shown in Fig. 18. A PD peak of about $500 \mathrm{~kW} / \mathrm{m}^{2}$ is obtained at the liner downstream end.

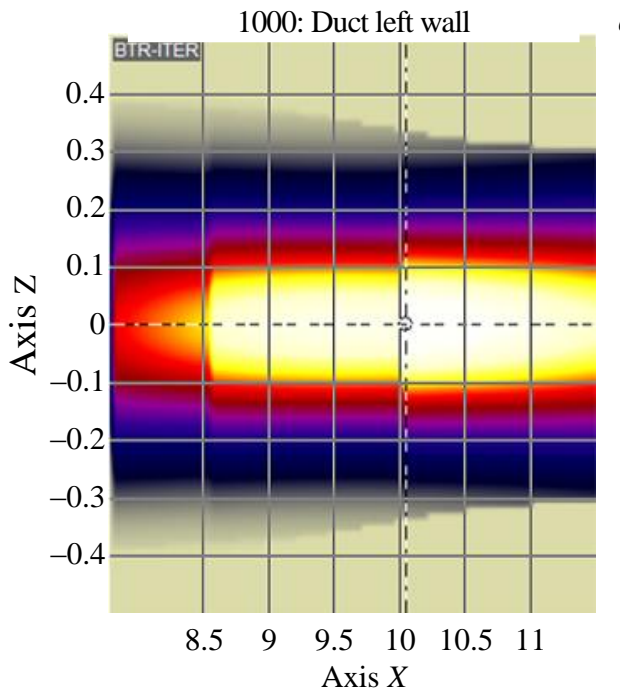

Total $=4.670 \cdot 10^{5} \mathrm{~W}, \operatorname{Max}=4.421 \cdot 10^{5} \mathrm{~W} / \mathrm{m}^{2}$
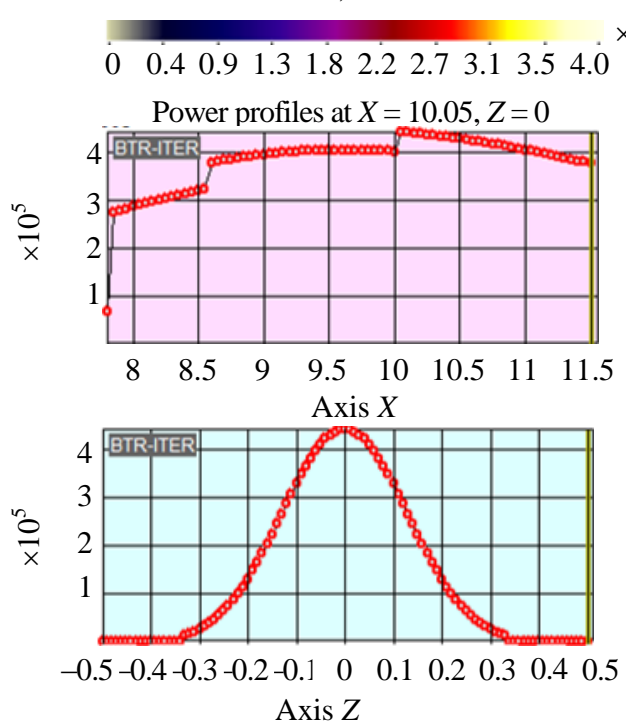

Axis $Z$

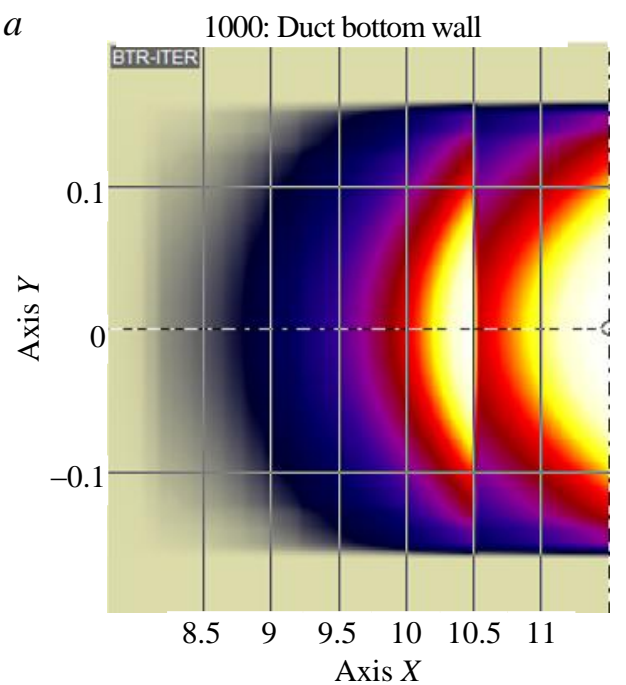

Total $=1.718 \cdot 10^{5} \mathrm{~W}, \mathrm{Max}=4.645 \cdot 10^{5} \mathrm{~W} / \mathrm{m}^{2}$

$\times 10^{5} \quad . \quad \times 10^{5}$

$\begin{array}{lllllllllllll}0 & 0.5 & 0.9 & 1.4 & 1.9 & 2.3 & 2.8 & 3.3 & 3.7 & 4.2 & \text { permissible misalignment }\end{array}$
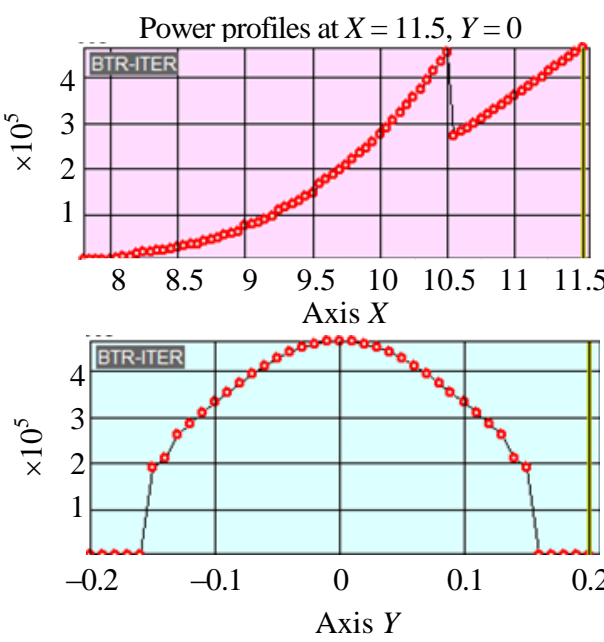

Fig. 18. NB duct liner dimensions $\left(X_{10}=7.8 \mathrm{~m}, W / H=\right.$ $=0.3 / 0.85 \mathrm{~m} ; \quad X_{11}=10.5 \mathrm{~m}$, $W / H=0.3 / 0.63 \mathrm{~m} ; X_{12}=11.5 \mathrm{~m}$, $W / H=0.3 / 0.6 \mathrm{~m}) \quad$ and $\quad$ the maximum load power and PD profiles on the left, $\alpha_{\mathrm{h}} / \alpha_{\mathrm{v}}=$ $=4 / 0 \operatorname{mrad}(a)$ and bottom, $\alpha_{\mathrm{h}} / \alpha_{\mathrm{v}}=0 /-6 \operatorname{mrad}(b)$ walls of the liner at the maximum angles 
Fig. 19 shows the PD profiles and the power values of the neutral beam entering the FNS-ST chamber for the ideal and the worst-case beam axis alignment. One can see that with an imperfect beam axis alignment, input power falls from 3.58 to $3.36 \mathrm{MW}$, while PD remains at its maximum of $\sim 44 \mathrm{MW} / \mathrm{m}^{2}$.
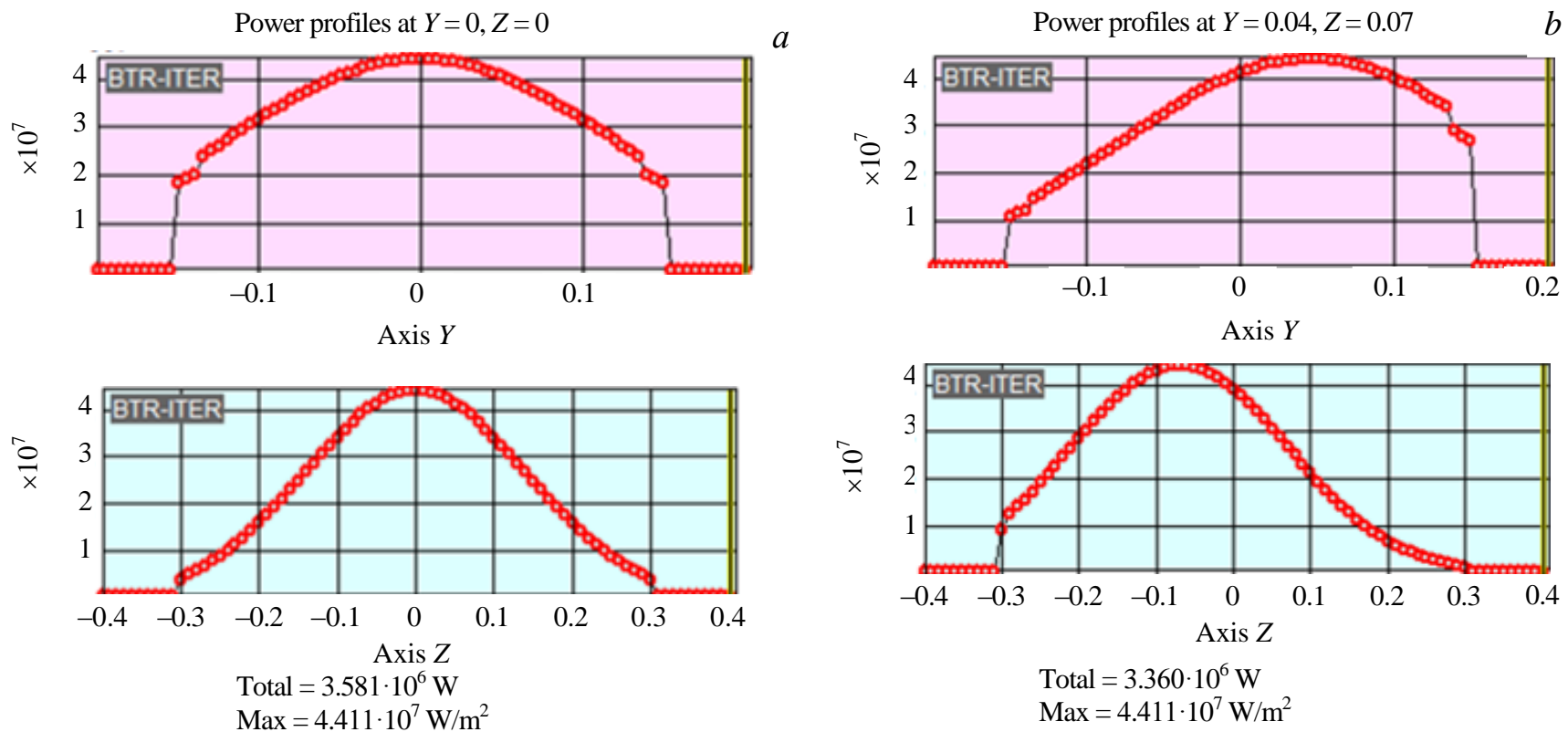

Fig. 19. Power density profiles of the neutral beam injected into the FNS-ST plasma for cases of ideal beam axisaligning, $\alpha_{\mathrm{h}} / \alpha_{\mathrm{v}}=0 / 0 \mathrm{mrad}(a)$ and for maximum values of misalignment angles, $\alpha_{\mathrm{h}} / \alpha_{\mathrm{v}}=4 /-6 \mathrm{mrad}(b)$

Table 2 shows the change in the beam power along the injection path and the distribution of loads to the path components, when the IS beam energy is $140 \mathrm{keV}$, for the ideal beam axis alignment to the injection axis and for the worst-case misalignment angles, $\alpha_{\mathrm{h}} / \alpha_{\mathrm{v}}= \pm 4 / \pm 6 \mathrm{mrad}$. As one can see from the table, the efficiency of NB transmission from the neutralizer to the tokamak plasma entrance, is $76 \%$ in the «ideal» case and drops to acceptable $71 \%$ in the «worst misalignment» case.

$\mathrm{T}$ a $\mathrm{b} l \mathrm{e}$ 2. Change in the beam power along injection path and load distribution to the path components (positive deuterium ions beam current from the ion source of $80 \mathrm{~A} ; \mathrm{D}^{+}: \mathrm{D}_{2}^{+}: \mathrm{D}_{3}^{+}$ionic makeup: $0,75: 0,15: 0,10$; divergence angle: $\pm 15 \mathrm{mrad}$ )

IS beam energy, keV
IS beam power, MW
Beam axis horizontal/vertical misalignment angle, mrad
Beam power load in the neutralizer, MW
Neutral beam power at the neutralizer exit, MW
Ion beam power at the neutralizer exit, MW
Power of the neutral beam load in the MRID, MW
Total power released in MRID (atoms + ions), MW
NB power at the exit from the MRID, MW
NB power intercepted by the scraper, MW
NB power load on the duct liner walls
NB power injected into the plasma, MW
Efficiency of NB transport to the plasma

Injector vacuum conditions. The gas (deuterium) flow rate in the injector VV is determined by required thickness, $\tau$, of the neutralizer gas target. As mentioned earlier, when neutralizing positive ions, the equilibrium yield of fast atoms is achieved at «infinite» $\tau$; therefore, $\tau$ is usually chosen that provides the atoms yield of $95 \%$ of the equilibrium one. The value of $\tau$ increases with increasing beam energy and for an energy of $140 \mathrm{keV}$ $\tau_{0.95}=1.26 \cdot 10^{20} \mathrm{~m}^{-2}$ (see Fig. 5). A neutralizer liner $2.5 \mathrm{~m}$ long connects two volumes: the SVV and the injector $\mathrm{VV}$, while the change in gas concentration/pressure along its axis is almost linear, and the pressure in the VV is negligible compared to the pressure in the SVV. Accordingly, the gas concentration in the SVV volume should be about $1 \cdot 10^{20} \mathrm{~m}^{-3}$, i.e., pressure $\sim 0.37 \mathrm{~Pa}$ (at a room temperature). With a liner section of $0.18 \times 1.2 \mathrm{~m}$ and a length of $2.5 \mathrm{~m}$, its conductivity is about $15 \mathrm{~m}^{3} / \mathrm{s}$ and the gas flow, providing the required $\tau_{0.95}$, will be $Q_{N}=5.6 \mathrm{~Pa} \cdot \mathrm{m}^{3} / \mathrm{s}$. The gas escaping from the ion source passes through the neutralizer, its flow will be about 
1.6 Pa $\cdot \mathrm{m}^{3} / \mathrm{s}$. Accordingly, an additional gas feed into the SVV is required at the level of $4 \mathrm{~Pa} \cdot \mathrm{m}^{3} / \mathrm{s}$. In addition, a residual ion beam with a current of about $55 \mathrm{~A}$ is dumped in the $\mathrm{VV}$, which, after neutralization on the MRID panel, gives a molecular deuterium flux of $0.65 \mathrm{~Pa} \cdot \mathrm{m}^{3} / \mathrm{s}$; so the total flow in the VV is about $6.3 \mathrm{~Pa} \cdot \mathrm{m}^{3} / \mathrm{s}$.

The pumping in the $\mathrm{VV}$ of the deuterium molecules at a rate of about $1.1 \cdot 10^{3} \mathrm{~m}^{3} / \mathrm{s}$ is carried out by cryosorption panels with a total area of $\sim 14 \mathrm{~m}^{2}$, located on the side walls of the VV. To reduce the NB loss in the region after the MRID due to the re-ionization of atoms due their collisions with the background gas molecules, the VV is divided into two parts using a vacuum baffle located in the MRID region. In this case, differential pumping is provided, which reduces the pressure in this section to $\sim 2.5 \cdot 10^{-3} \mathrm{~Pa}$. According to estimates, the re-ionization losses of the NB will be $\sim 7 \%$ (about $0.24 \mathrm{MW}$ ).

The duration of the injector continuous operation is limited on account of the explosion hazard. Gas evacuated from the VV freezes on cryopanels, and a critical value may be reached, in which event an atmospheric air breakthrough into the VV and the cryopanels rapid warming may occur, giving rise to an «explosive mixture». In accordance with explosion safety provisions, deuterium content in the mixture under normal conditions must not exceed $2 \%\left(2 \cdot 10^{3} \mathrm{~Pa}\right)$. Considering that the VV and SVV total volume is $25 \mathrm{~m}^{3}$, gas accumulated on cryopanels must not exceed $5 \cdot 10^{4} \mathrm{~Pa} \cdot \mathrm{m}^{3}$. Consequently, at a gas flow of $6.3 \mathrm{~Pa} \cdot \mathrm{m}^{3} / \mathrm{s}$, the injector must be brought to a halt after 2.2 hours of operation to regenerate the cryopanels, and must be ready to resume operation in $\sim 45$ min to make sure that NB power injection into the tokamak is uninterrupted.

\section{CONCLUSION}

Strengths and weaknesses of positive- or negative-ion-based fast deuterium neutral beam injectors for FNS-ST have been analyzed and compared with the assumption of their applicability to the «intermediate» beam energy range of $100-200 \mathrm{keV}$. It has been shown that a negative- deuterium-ion-based system has significant advantages over the positive ion technology at ion energies above $150 \mathrm{keV}$, whereas at lower energies the situation is vice versa.

As is shown in [6], in the case of a small-sized FNS-ST, the attenuation of an $>140 \mathrm{keV}$ neutral beam during its moving in the tokamak plasma is insufficient in terms of its power release on the first wall. Consequently, the injection module for the FNS-ST should be a positive- deuterium-ion-based system allowing the delivery of 3.5 MW deuterium neutral beam power to plasma at an ion source energy of 100-140 keV and source ion current of $80 \mathrm{~A}$.

Calculations of the efficiency of beam transmission to the tokamak plasma were done for different beam geometries. The ion beam configuration at the IS exit was chosen in the form of a five-section vertically elongated $0.15 \times 1.15 \mathrm{~m}$ «ribbon» with each section focused onto the tokamak $0.3 \times 0.6 \mathrm{~m}$ entrance window. Power loads on the beam path components were calculated, and the efficiency of NB transport was found to be $75 \%$.

A compact system of residual ion beam horizontal deflection by a vertical magnetic field onto a dump panel inside the magnetic system is considered. At a $140 \mathrm{keV}$ source ion energy, the fraction of residual ions is about $60 \%$, therefore, peak power density, $\mathrm{PD}_{\max }$, at the dump panel reaches $15 \mathrm{MW} / \mathrm{m}^{2}$.

The dump panel, as well as calorimeter panels with a $\mathrm{PD}_{\max }$ of $10 \mathrm{MW} / \mathrm{m}^{2}$, falls into the class of receivers with critical heat fluxes (CHF), whose design uses hardened chrome-zirconium bronze tubes with twisted tape heat removal intensifiers. The configurations of the other injector components are selected such that $\mathrm{PD}_{\max }$ is within $0.5 \mathrm{MW} / \mathrm{m}^{2}$.

The working gas (deuterium) supplied to the neutralizer and the ion source is pumped at a rate of about $1 \cdot 10^{3} \mathrm{~m}^{3} / \mathrm{s}$ using cryopanels, placed inside the injector vacuum vessel. The duration of the injector continuous operation is limited on account of the explosion hazard. At a gas flow of $6.3 \mathrm{~Pa} \cdot \mathrm{m}^{3} / \mathrm{s}$, the amount of gas accumulated on the cryopanels should not exceed $5 \cdot 10^{4} \mathrm{~Pa} \cdot \mathrm{m}^{3}$, i.e. the injector must stop operation after 2.2 hours to regenerate the cryopanels. If NBIS FNS-ST uses four injectors, they should be enabled alternately, so that with three units in operation one is in the cryopump regeneration mode. The latter should be ready to resume operation in $\sim 45$ minutes to make sure that NB power injection into the tokamak is uninterrupted.

This work was supported by the National Research Center «Kurchatov Institute» (28.09.2020 № 1934a). 


\section{REFERENCES}

1. Kuteev B.V. et al. Steady state operation in compact tokamaks with copper coils. — Nucl. Fusion, 2011, vol. 51, p. 073013.

2. Goncharov P.R. et al. Comparison between neutron yields of classical and spherical tokamaks. — VANT. Ser. Termoyadernyi sintez (Problems of Atomic Science and Technology. Ser. Thermonuclear Fusion), 2011, issue 2, p. 36- 43 (in Russian).

3. Dnestrovskiy A.Yu., Golikov A.A., Kuteev B.V. et al. The investigation of the steady state regime for the tokamak neutron source. - VANT. Ser. Termoyadernyi sintez (Problems of Atomic Science and Technology. Ser. Thermonuclear Fusion), 2010, issue 4, p. 26-35 (in Russian).

4. ORNL «Red Book», 1977.

5. ITER Final Design Report, DDD 5.3, 2001.

6. Dlougach E.D. Neutral beam current ratio in the neutron source FNS-ST. - VANT. Ser. Termoyadernyi sintez (Problems of Atomic Science and Technology. Ser. Thermonuclear Fusion), 2021, vol. 44, issue 1, p. 68-79 (in Russian).

7. Naumov V.K., Semashko N.N., Komov A.T. et al. Method of adiabatic cross-section and its application for estimating of thermophysical and thermo-strength parameters of high density beam dumps. — Plasma Devices and Operations, 1999, vol. 8, p. 39—65.

8. Ananyev S.S., Dlougach E.D. et al. Modeling and optimization of the neutral beam line for plasma heating and current drive for the DEMO-FNS fusion neutron source project. - Fusion Engineering and Design, 2020, vol. 161, p. 112064.

\section{AUTHORS}

Alexander A. Panasenkov, PhD head scientist, NRC «Kurchatov Institute», 1, Academika Kurchatova sq., Moscow, 123182, Russia, Panasenkov_AA@nrcki.ru

Sergey S. Ananyev, Leading Researcher, PhD in physics and mathematics, NRC «Kurchatov Institute», 1, Academika Kurchatova sq., Moscow, 123182, Russia, Ananyev_SS@nrcki.ru

Eugenia D. Dlougach, senior scientist, NRC «Kurchatov Institute», 1, Academika Kurchatova sq., Moscow, 123182, Russia, edlougach@gmail.com

Boris V. Kuteev, Professor, Deputy Head Tokamak Department Fusion Research Centre; NRC «Kurchatov Institute», 1, Academika Kurchatova sq., Moscow, 123182, Russia, Kuteev_BV@ nrcki.ru

Received 15 January 2021

Revised 16 March 2021

Accepted 25 March 2021

Problems of Atomic Science and Technology Ser. Thermonuclear Fusion, 2021, vol. 44, issue 2, pp. 86-99 